\title{
Defined Study Administrative Activity
}

National Cancer Institute

\section{Source}

National Cancer Institute. Defined Study Administrative Activity. NCI Thesaurus. Code C93375.

An administrative activity defined at a global library level that represents a study level administrative activity that is independent of a study subject. 